\section{Cracks shut neutron reactor}

\section{London}

DAMAGE to components in a French nuclear reactor facility last week forced officials to close the world's most powerful neutron source for repairs that are expected to keep the machine - and many of its 2,500 users - out of commission for two years.

Officials at the Insitut Max von LauePaul Langevin in Grenoble first discovered cracks in a grid of the reactor, which is the heart of a thermal neutron generating facility, as part of a routine televisioncamera inspection in April, according to institute spokesman Brend Meyer. The that smoothes the flow of heavy water after it leaves the reactor. It seems that the lower of the two grids came loose and was pushed up into the higher grid. Officials suspect that radiation-induced brittleness in the grid material allowed it to crack under the strain.

"We first tried to readjust the lower grid. But when they tried to get the bolts out, they failed completely. Whether because of radiation or just corrosion, the bolts can't be loosened," Meyer said. Repairing or replacing the unit is likely to take at least two years, and even longer if the reactor must be drained of its heavy water.

The facility is used by more than 2,500 researchers, from biologists to material scientists, who visit the Grenoble facility for its powerful neutron beam. Scientists use the neutrons for basic research into neutron properties, as a 'microscope' to investigate the atomic structure of materials, and to examine viruses and biolocation. accommodating new users. the facility by over a decade. damaged grid is part of a two-grid baffle

gical membranes at unparalleled magnifi-

Although there are several other large neutron sources in Europe, none can match Grenoble's flux $-1.5 \times 10^{15}$ neutrons $\mathrm{cm}^{-2} \mathrm{~s}^{-1}$. Some users may be able to use the Saclay source in Paris, but a large new source at the Berlin HMI Institute that is closer to Grenoble's power is not yet running. Recently the European Communities, recognizing Europe's disproportionate reliance on Grenoble for neutron physics, gave the green light to upgrade a small Danish reactor at the Risloe research institute. But that is not yet completed, and the untimely failure of Grenoble will only reinforce the need for new facilities.

In the United Kingdom, the Rutherford-Appleton Laboratory's large neutron source would be a natural choice to absorb some of Grenoble's users, were it not for the fact that it is already oversubscribed by a factor of three. Government funding cuts threaten the facility's future, and laboratory officials are not eager to stretch their scarce resources on

Late last week, officials from the three countries (the United Kingdom, France and Germany) that cooperatively run the Grenoble facility agreed - subject to approval by their governments - to use the shutdown as an opportunity to install a completely new reactor at the laboratory by 1994. Although it would be functionally identical to the existing reactor, a new reactor could extend the lifespan of

Christopher Anderson

\section{GERMAN SCIENCE}

\section{DFG selects new president}

\section{Constance, Germany}

AT its annual meeting in Constance last week, the German grant agency Deutsche Forschungsgemeinschaft (DFG) selected Wolfgang Früwald, a German language and literature scholar, as its new president.

Frühwald immediately announced that his priorities for expansion in the next few years will be biomedical research, molecular biology, and especially clinical medical research, where Germany, he said, has yet to become internationally competitive.

Frühwald will begin a three-year term as president in January 1992, succeeding ethologist Hubert Markl. Frühwald is the first DFG president since 1964 not to be a natural scientist. With legal scholar Hans Zacher as current president of the Max Planck Gesellschaft, two of the largest research organizations in Germany are now led by non-natural scientists.
On the future location of DFG, Frühwald says he thinks it likely that the organization will remain in Bonn even though the parliament and government are moving to Berlin. He supports the idea, currently in vogue in Bonn, to make Bonn a "science city", but he warns that this can be achieved only through a concerted effort by politicians and the scientific community, and not just by leaving a few scientific bureaucrats in Bonn after the move.

With an annual budget (in 1991) of DM1,300 million, DFG is the single largest provider in Germany of university research grants and also pays for thousands of stipends for doctoral and postdoctoral students. Supported by both the federal government and the Länder, DFG funds research in all fields, including both natural sciences and the humanities.

Steven Dickman
Mystery solved in US phone failures

\section{Washington}

THE cause of a string of major breakdowns in local phone service in several areas of the United States has been identified: a 'bug' in the switching program consisting of three or four faulty lines of computer code among the millions of lines that constitute the software.

Frank Perpiglia, vice president of DSC Communications Corporation, the supplier of the switching computers, said last week that the company had made minor changes in the software provided to several local telephone companies. DSC deemed the changes to be so minor as to not demand the normal thorough testing that switches are subjected to, he said.

That judgment proved faulty. On 26 June, some six million customers in Washington and Baltimore lost their local telephone service for more than six hours, and on the same afternoon three million residents of the Los Angeles area were without a local telephone service for three hours. On 1-2 July, Pittsburgh experienced two failures lasting a total of nine hours, and San Francisco was saved from a massive telephone blackout by telephone company engineers who shut down a misfiring switch before it could trigger other failures.

The pattern of the crashes was nearly identical. A minor failure in one switching computer led to a growing series of error messages being exchanged between switches, until the error messages - which have priority over telephone calls crowded out normal telephone traffic.

At first, officials from DSC and the various local telephone companies doubted that the software could be to blame, because DSC provided different versions of the software to the different telephone companies, and because, while the software was shipped out from the beginning of March and installed at various times, the breakdowns struck within a matter of days in widely separated areas of the country.

It now seems that each version of the software had the same bug, but the near simultaneity of the crashes must be chalked up to coincidence.

DSC provided software patches that it says should prevent any recurrence of the telephone failures, but concern remains about the vulnerability of increasingly complex phone systems to breakdowns as well as to deliberate sabotage - something that telephone company officials do not believe was a factor in this case. Last week, for instance, the Federal Communications Commission said that it has decided to increase its own research into the reliability of telecommunications networks.

Robert Pool 